\title{
Семейство Crassulaceae J. St.-Hil. в коллекции оранжереи Полярно-альпийского ботанического сада
}

\section{The family Crassulaceae J. St.-Hil. in the greenhouse collection of the Polar-alpine botanical garden}

\author{
Иванова Л. А., Вирачева Л. Л. \\ Ivanova L. A., Viracheva L. L. \\ Полярно-альпийский ботанический сад-институт им. Н. А. Аврорина, г. Anamuты, Россия. E-mail: ivanova_la@inbox.ru \\ Avrorin polar-alpine botanical garden-institute, Apatity, Russia
}

\begin{abstract}
Peферат. В статье дана характеристика коллекционных растений семейства Crassulaceae J. St.-Hil. Полярно-альпийского ботанического сада КНЦ РАН. В настоящее время коллекция насчитывает 46 таксонов (44 - виды и разновидности, и 2 - сорта), относящихся к 7 родам. В коллекции представлены следующие жизненные формы: деревья - 6 видов, кустарники и кустарнички - 11, травы - 25, среди которых выделены разные морфологические типы. Особенность толстянковых - образование выводковых почек по краю листа или в соцветии, которые можно использовать для вегетативного размножения.
\end{abstract}

Ключевые слова. Жизненные формы, Кольский полуостров, рост и развитие растений, Толстянковые, фенология.

Summary. The characteristic of the plant collection of family Crassulaceae J. St.-Hil. in Polar-alpine botanical garden is given in the article. Now it includes 46 taxa belonging to 7 genera. Different life forms (trees -6 species, shrubs 11 species, herbaceous plants -25 species) and various morphological types are presented in the collection. The peculiarity of Crassulaceae is the formation of brood buds along the leaf edge or in the inflorescence, which can be used for vegetative propagation.

Key words. Crassulaceae, Kola Peninsula, life forms, phenology, plant growth and development.

Семейство толстянковых (Crassulaceae J. St.-Hil.) насчитывает около 1500 видов суккулентных растений, относящихся к 35 родам (Тахтаджян, 1987). Родиной большинства из них являются теплые засушливые области Африки, Мадагаскара, Центральной Америки.

Растения семейства толстянковых относятся к наиболее декоративным суккулентам. Большинство видов используется в озеленении интерьеров и в открытом грунте. Из-за оригинальности внешнего облика, необычных толстых листьев, окраска которых может варьировать от серо-серебристой до темно-бордовой, долго сохраняющихся на растении соцветий (яркие, от белых до красных) толстянковые часто выращивают как комнатные растения. В культуру введено много гибридных форм и культиваров. В декоративных целях в интерьерах эти суккуленты используют и как ампельные, и как почвопокровные растения. Они хороши и для контейнерной посадки как самостоятельные растения, так и в составе суккулентных флористических композиций.

Среди растений семейства толстянковых имеются ценные лекарственные растения. Так, например, более 400 лет популярным средством народной медицины является родиола розовая, или золотой корень (Rhodiola rosea). Эониум бальзамический (Aeonium. balsamifera) и эониум пальмский (A. palmense) выделяются среди видов рода эониум содержанием бальзама в листьях. Листья каланхое (бриофиллум) Дегремона (Kalanchoё daigremontiana) и каланхое перистое (K. pinnatum) используют в быту при самых разных заболеваниях, их называют «деревом жизни» или «комнатным женьшенем» (Гончарова и др., 2011).

Полярно-альпийский ботанический сад-институт им. Н. А. Аврорина КНЦ РАН (ПАБСИ) единственный ботанический сад, расположенный в полярных широтах нашей страны, и один из не- 
многих в мире альпийских (высокогорных) садов. Он находится в Мурманской области, на Кольском полуострове, в Хибинском горном массиве (6730' с.ш. $33^{\circ} 40^{\prime}$ в.д.), который простирается на 150 км севернее Полярного круга.

Интродукция толстянковых в теплицах ПАБСИ начата в середине 50-х гг. ХХ в. (Козупеева, Лештаева, 1979). В настоящее время они выращиваются в специализированной оранжерее площадью $150 \mathrm{M}^{2}$, построенной в соответствии с типовым проектом Гипронисельпрома, имеющей двускатное поликарбонатное покрытие и высоту в коньке 3 м. Теплица оснащена специализированным оборудованием для многолетней эксплуатации и с учетом специфики выращивания растений в условиях интродукционных экспериментов.

Исходный материал (семена, живые растения и черенки) был получен из зарубежных и отечественных ботанических садов в порядке обмена, от цветоводов-любителей или приобретен через торговую сеть.

Изучение особенностей роста и развития растений позволили оценить адаптационные возможности суккулентных растений и перспективы их дальнейшего использования. Для выявления сезонного ритма развития растений проводились фенологические наблюдения (Методика..., 1979).

Коллекция растений семейства Crassulaceae в ПАБСИ в настоящее время насчитывает 45 видов и разновидностей и 2 сорта, относящихся к 7 родам (табл.). А. Л. Тахтаджян (1987) делит сем. Crassulaceae на 4 подсемейства. Все они представлены в коллекции: Sedoideae: роды Aeonium Webb et Berthel., Monanthes Haw., Sedum L.; Echeverioideae: роды Echeveria DC, Graptoprtalum Rose, Pachyphytum Link.; Kalanchoideae: Kalanchoё Adans; Crassuloideae: Crassula L. На родовом уровне более богатым видовым составом отличаются роды Crassula (9 видов), Kalanchoё (14 видов) и Sedum (11 видов), остальные насчитывают от 1 до 3 видов.

Таблица

Итоги интродукции растений семейства Crassulaceae J. St.-Hil.

в Полярно-альпийском ботаническом саду

\begin{tabular}{|c|c|c|c|}
\hline Виды & $\begin{array}{c}\text { Годы } \\
\text { испытания }\end{array}$ & $\begin{array}{c}\text { Количество } \\
\text { образцов }\end{array}$ & $\begin{array}{c}\text { Конечная } \\
\text { фаза развития }\end{array}$ \\
\hline Aeonium domesticum (Praeg.) Bgr. & c 1993 & 1 & B \\
\hline Aeonium haworthii (SD.) Webb et Berth. & c 1986 & 1 & $\mathrm{~B}$ \\
\hline Aeonium lindleyi Webb et Berth. & c 1995 & 1 & $\mathrm{~B}$ \\
\hline Aeonium lindleyi Webb et Berth. var. viscatum (Bolle) H.Y. Liu & c 1995 & 1 & $\mathrm{~B}$ \\
\hline Crassula arborescens (Mill.) Willd. & c 1995 & 1 & $\mathrm{~B}$ \\
\hline Crassula cordata Thunbg. & c 1980 & 1 & Ц \\
\hline Crassula falcata Wendl. & c 1992 & 1 & $\mathrm{~B}$ \\
\hline Crassula lactea Sol. & c 1956 & 1 & Ц \\
\hline Crassula orbicularis $\mathrm{L}$. & c 2005 & 1 & $\mathrm{~B}$ \\
\hline Crassula ovata (Mill.) Druce & c 1960 & 1 & Ц \\
\hline Crassula ovata (Mill.) Druce cv. Gollum & c 2003 & 1 & $\mathrm{~B}$ \\
\hline Crassula pellucida L. ssp. marginalis (Sol. ex Aiton) Toelken & c 1980 & 2 & $\mathrm{~B}$ \\
\hline Crassula perforata Thunb. & c 1980 & 1 & Ц \\
\hline Crassula sarmentosa Harv. & c 1976 & 1 & B \\
\hline Echeveria elegans Rose & c 1975 & 1 & Ц \\
\hline Echeveria leucotricha J.A. Purp. & c 1980 & 1 & $\mathrm{~B}$ \\
\hline Echeveria secunda Booth & c 1956 & 1 & Ц \\
\hline Graptopetalum macdougalli Alexander & c 1980 & 1 & B \\
\hline Kalanchoë beharensis Drake et Castillo & c 1992 & 1 & $\mathrm{~B}$ \\
\hline Kalanchoë blossfeldiana van Poelln & c 1984 & 1 & $\Pi$ \\
\hline Kalanchoë blossfeldiana van Poelln cv. Yellow & c 1984 & 1 & $\Pi$ \\
\hline Kalanchoë crenata (Andrews.) Haw. & c 1994 & 1 & Ц \\
\hline Kalanchoë daigremontiana Hamet et Perr. & c 1957 & 1 & Ц \\
\hline
\end{tabular}


Таблица

\begin{tabular}{|c|c|c|c|}
\hline Виды & $\begin{array}{c}\text { Годы } \\
\text { испытания }\end{array}$ & $\begin{array}{c}\text { Количество } \\
\text { образцов }\end{array}$ & $\begin{array}{c}\text { Конечная } \\
\text { фаза развития }\end{array}$ \\
\hline Kalanchoë faustii Font y Quer & c 1993 & 1 & $\Pi$ \\
\hline Kalanchoë fedtschenkoi Hamet et Perr. & c 1966 & 1 & Ц \\
\hline Kalanchoë lobata R. Fernandes & c 1992 & 1 & Ц \\
\hline Kalanchoë longiflora Schltr. & c 1993 & 1 & Ц \\
\hline Kalanchoë marnieriana Jacobs. & c 1979 & 1 & Ц \\
\hline Kalanchoë orgyalis Bak. & c 1994 & 1 & $\mathrm{~B}$ \\
\hline Kalanchoë pumila Bak. & c 1994 & 1 & Ц \\
\hline Kalanchoë schimperiana A. Rich. & c 1996 & 1 & B \\
\hline Kalanchoë tomentosa Bak. & c 1968 & 1 & $\mathrm{~B}$ \\
\hline Kalanchoë tubiflora (Harv.) Hamet & c 1992 & 1 & $\Pi$ \\
\hline Monanthes muralis (Webb) Christ & c 1985 & 1 & Ц \\
\hline Pachyphytum compactum Rose & c 1980 & 1 & $\mathrm{~B}$ \\
\hline Sedum burrito Moran & c 1992 & 1 & $\mathrm{~B}$ \\
\hline Sedum clavifolius Rose & c 1993 & 1 & $\mathrm{~B}$ \\
\hline Sedum glaebosum Fröd. & c 2018 & 1 & B \\
\hline Sedum hultenii Fro & c 1980 & 1 & Ц \\
\hline Sedum mexicanum Britt. & c $1987-1990$ & 1 & $\mathrm{~B}$ \\
\hline Sedum morganianum E. Walth. & c 1976 & 1 & Ц \\
\hline Sedum nussbaumerianum Bitter & c 1980 & 1 & $\mathrm{~B}$ \\
\hline Sedum palmeri S. Wats. & c 1957 & 1 & $\Pi$ \\
\hline Sedum stenopetalum Pursh & c 2018 & 1 & $\mathrm{~B}$ \\
\hline Sedum treleasei Rose & c 1985 & 1 & $\mathrm{~B}$ \\
\hline Sedum sp. & c 2010 & 1 & B \\
\hline
\end{tabular}

Примечание: В - вегетация, Ц - цветение, П - плодоношение.

Основная масса представленных в коллекции толстянковых в природе произрастает в Африке - 27 видов: Канарские о-ва - все виды рода Aeomium и Monanthes muralis; Мадагаскар - многие из рода Kalanchoё (K. beharensis, K. blossfeldiana, K. daigremontiana, K. marnieriana, K. orgyalis, K. pumila, K. tomentosa); Капская флористическая область - все виды рода Crassula и Kalanchoё longiflora; тропические районы Африки - виды рода Kalanchoё (K. crenata, K. faustii, K. lobata, K. schimperiana, K. tubiflora). 14 видов происходят из Северной Америки: из США - Kalanchoё fedtschenkoi и Sedum stenopetalum; из Мексики - виды рода Echeveria, Pachyphytum compactum и виды рода Sedum (S. burrito, S. clavifolius, S. hultenii, S. mexicanum, S. morganianum, S. nussbaumerianum, S. palmeri, S. treleasei). Азиатский континент представлен 1 видом - Sedum glaebosum из Китая.

Среди коллекционных растений встречаются разные жизненные формы: деревья, кустарники, кустарнички и травы (Тахтаджян, 1966). Е. С. Смирнова (1971) на основании трех признаков (направление роста побегов, образующих систему основной оси, форма основной оси, способ ветвления побега в целом) среди растений семейства толстянковых выделила несколько морфологических типов. Согласно этой классификации, в ПАБСИ имеются два: ортотропный и плагиотропный морфологические типы.

В состав ортотропных растений входят:

Кустарники:

1. Плейохазиальный кустарник с простыми стеблями: Crassula perforata, Kalanchoё crenata, K. faustii, K. longiflora.

2. Плейохазиальный кустарник с ветвящимися стеблями: Kalanchoё fedtschenkoi, K. marnieriana, K. orgyalis, K. pumila.

3. Монохазиальный кустарник: Crassula falcata, Kalanchoё daigremontiana, K. tubiflora. 
Короткометамерные деревья:

1. Монохазиальное короткомерное дерево: Kalanchoё beharensis.

Кустовидные короткометамерные деревья:

1. Плейохазиальное кустовидное короткометамерное дерево: Crassula arborescens, C. cordata, C. ovata.

2. Плейохазиальное короткометамерное вершиннорозеточное дерево: Aeonium haworthii, A. lindleyi.

Розеточные растения:

1. Плейохазиальное розеточное растение: Crassula orbicularis, C. pellucida ssp. marginalis.

2. Моноподиальное розеточное растение: Echeveria elegans, E. leucotricha, E. secunda, Graptopetalum macdougalli.

Плагиотропные растения представляют:

Длиннометамерные травы:

1. Плейохазиальные длиннометамерные растения: Crassula lactea, C. sarmentosa, Sedum burrito, S. glaebosum, S. mexicanum, S. morganianum, S. stenopetalum.

Кустовидные длиннометамерные травы:

1. Плейохазиальная кустовидная длиннометамерная трава: Kalanchoё blossfeldiana, K. lobata, K. schimperiana, K. tomentosa, Sedum clavifolius, S. nussbaumerianum, S. treleasei.

2. Дихазиальная кустовидная длиннометамерная трава: Aeonium domesticum.

Короткометамерные травы:

1. Плейохазиальная короткометамерная трава: Monanthes muralis.

2. Монохазиальная короткометамерная трава: Sedum hultenii, S. palmeri.

3. Моноподиальная короткометамерная трава: Pachyphytum compactum.

Фенологические наблюдения показали, что в условиях закрытого грунта Кольского Заполярья регулярное и устойчивое цветение наблюдается у 11 видов толстянковых: Crassula cordata, C. lactea, Echeveria elegans, E. leucotricha, E. secunda, Kalanchö̈ blossfeldiana, K. daigremontiana, K. faustii, K. pumila, K. tubiflora, Sedum palmeri. Периодически цветут Crassula ovata, C. perforata, Kalanchoё crenata, K. fedtschenkoi, K. lobata, K. longiflora, K. marnieriana, Monanthes muralis, Sedum hultenii. Отмечено единичное цветение Sedum morganianum. Семена вызревали у трех видов рода Kalanchoё (K. blossfeldiana, K. faustii, K. tubiflora) и Sedum palmeri. Большая половина растений коллекции находится в вегетативном состоянии. Поэтому преобладает вегетативный способ размножения:

1. За счет выводковых почек, образующихся по краю листа (Kalanchoё crenata, K. daigremontiana, K. faustii, K. tubiflora) или в соцветии (Crassula cordata);

2. Листовыми черенками (Crassula falcata, C. ovata, Pachyphytum compactum Sedum burrito, S. clavifolius, $S$. morganianum, $S$. nussbaumerianum, S. treleasei);

3. Стеблевыми черенками (большинство видов).

На основании вышесказанного были сделаны следующие выводы:

1. Семейство Crassulacea в коллекции ПАБСИ представлено всеми жизненными формами (деревья - 6 видов, кустарники и кустарнички - 11 видов, травы - 25 видов), среди которых можно выделить два морфологических типа: ортотропный и плагиотропный.

2. В условиях закрытого грунта Кольского Заполярья регулярно цветут 11 видов толстянковых, периодически - 9, единичное цветение наблюдается только у 1 вида толстянковых.

3. Семена вызревали у трех видов рода Kalanchoё (K. blossfeldiana, K. faustii, K. tubiflora) и Sedum palmeri. Большая половина растений коллекции находится в вегетативном состоянии. 
4. Размножаются растения преимущественно вегетативным способом: выводковыми почками, листовыми и стеблевыми черенками.

\section{ЛИТЕРАТУРА}

Козупеева T. A., Лештаева $\boldsymbol{A}$. $\boldsymbol{A}$. Тропические и субтропические растения на Полярном Севере (Краткие итоги интродукции в оранжереях Полярно-альпийского ботанического сада). - Л.: Наука, 1979. - 150 с.

Гончарова С., Колдаева М., Белуха А. Дальневосточные толстянковые в культуре // Цветоводство. - 2011. - № 5. C. $9-10$.

Методика фенологических наблюдений в ботанических садах СССР // Бюл. Гл. ботан. сада, 1979. - Вып. 113. - C. 3-8.

Cмирнова $\boldsymbol{E}$. $\boldsymbol{C}$. Морфологические типы многолетних цветковых растений тропиков и субтропиков // Журнал общей биологии, 1970. - Т. 11. - № 5. - С. 578-588.

Смирнова $\boldsymbol{E}$. $\boldsymbol{C}$. Морфологические типы вегетативной сферы растений семейства Crassulaceae // Бюл. Моск. о-ва испыт. природы. Отд. биолог., 1971. - Т. 75. - Вып. 2. - С. 89-97.

Тахтаджян А. Л. Система и филогения цветковых растений. - М.-Л.: Наука, 1966. - 611 с.

Tахтаджсян А. Л. Система магнолиофитов. - Л.: Наука, 1987. - 338 с. 